\title{
Inhibition of lung cancer cells and Ras/Raf/ MEK/ERK signal transduction by ectonucleoside triphosphate phosphohydrolase-7 (ENTPD7)
}

Zhongwei Wen, Rongfang Jiang, Ying Huang, Zhineng Wen, Dong Rui, Xiaoxiao Liao and Zhougui Ling* (D)

\begin{abstract}
Background: The aim of this study was to investigate the effects and mechanisms of ectonucleoside triphosphate phosphohydrolase-7 (ENTPD7) on lung cancer cells.

Methods: The expression characteristics of ENTPD7 and its effect on the survival of lung cancer patients were analyzed by referring to The Cancer Genome Atlas (TCGA). Streptavidin-peroxidase (SP) staining was performed to detect the ENTPD7 protein in tumor tissues and adjacent tissues. Plasmid transfection technology was also applied to silence ENTPD7 gene. Crystal violet staining and flow cytometry were performed to determine cell proliferation and apoptosis. Tumor-bearing nude mice model was established to investigate the effect of sh-ENTPD7 on tumors.

Results: The results showed that patients with low levels of ENTPD7 had higher survival rates. ENTPD7 was up-regulated in lung cancer tissues and cells. Down-regulation of the expression of ENTPD7 inhibited proliferation but promoted apoptosis of lung cancer cell. Silencing ENTPD7 also inhibited the expression levels of Ras and Raf proteins and the phosphorylation of mitogen-activated protein kinase (MEK) and extracellular signal-regulated kinase (ERK). Tumor-bearing nude mice experiments showed that silencing ENTPD7 had an inhibitory effect on lung cancer cells.
\end{abstract}

Conclusions: ENTPD7 was overexpressed in lung cancer cells. Down-regulating ENTPD7 could inhibit lung cancer cell proliferation and promote apoptosis via inhibiting the Ras/Raf/MEK/ERK pathway.

Keywords: Lung cancer, Ectonucleoside triphosphate phosphohydrolase-7, Proliferation, Senescence

\section{Background}

Lung cancer is one of the most lethal malignant tumors. According to statistics from the American Cancer Society, lung cancer had the second highest incidence and the highest mortality rate in the United States in 2017 [1, 2]. Lung cancer is divided into small cell lung cancer (SCLC) and nonsmall cell lung cancer (NSCLC), with NSCLC accounting for about $80 \%$ of all cases [3]. Surgery, radiotherapy, chemotherapy and immunotherapy are the main methods for treating lung cancer, though the outcome of those methods is quite different [4]. Infiltration and distant metastasis in situ often occur to patients with lung cancer, and the 5-year survival

\footnotetext{
* Correspondence: Lzg2218@163.com

Department of Respiratory and Critical Care Medicine, the Fourth Affiliated Hospital of Guangxi Medical University, No. 1 Liushi Road, Liuzhou 545005, Guangxi Province, China
}

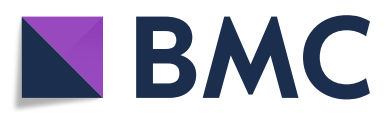

(c) The Author(s). 2019 Open Access This article is distributed under the terms of the Creative Commons Attribution 4.0 International License (http://creativecommons.org/licenses/by/4.0/), which permits unrestricted use, distribution, and reproduction in any medium, provided you give appropriate credit to the original author(s) and the source, provide a link to the Creative Commons license, and indicate if changes were made. The Creative Commons Public Domain Dedication waiver (http://creativecommons.org/publicdomain/zero/1.0/) applies to the data made available in this article, unless otherwise stated.

rate of patients is still low [5-7]. Moreover, although tyrosine kinase inhibitor (TKI) was well developed in recent years, the problem of high recurrence rate still exists [8].

The activation of tyrosine kinase receptor-associated signaling system plays an important role in the development and progression of lung cancer. Ras/Raf/mitogen-activated protein kinase (MEK)/extracellular signal-regulated kinase (ERK) regulates a variety of cellular processes including proliferation and apoptosis [9, 10]. Recent studies have found that Ras/Raf/MEK/ERK pathway also plays a critical role in regulating cellular senescence [11-13].

Cellular senescence is a state of cell cycle arrest initiated by various stimuli such as telomere shortening, oncogenes, or chemotherapies, and senescence can occur after cell proliferation (replication of senescence) or immediately after acute stress [14, 15]. Ecto-nucleoside triphosphate 
diphosphohydrolase (ENTPDase) family consists of eight members that regulate extracellular Adenosine Triphosphate (ATP) level and participates in cellular activities [16]. Study found that ectonucleoside triphosphate phosphohydrolase-7 (ENTPD7) played an important role in inhibiting cellular senescence in liver cancer [17]. However, to the best of our knowledge, no research has been conducted on the role of ENTPD7 in lung cancer.

Therefore, this study mainly explored the expression characteristics of ENTPD7 in lung cancer, the effects of ENTPD7 on the proliferation and apoptosis of lung cancer cells and the mechanism of action. Our study provides a new understanding on the treatment of lung cancer.

\section{Methods}

\section{Bioinformatics analysis}

The mRNA expression level of ENTPD7 and different tumor node metastasis (TNM) stages were downloaded from The Cancer Genome Atlas (TCGA) database. The mRNA expression levels of ENTPD7 in different lung cancer stages were determined using TCGA, and weighted gene co-expression network analysis (WGCNA) was applied to conduct correlation analysis of the expressions of ENTPD7 and survival rate.

\section{Patients and samples}

From July 2015 to July 2016, lung cancer tissues and adjacent tissues were collected from 24 males and 20 females (aged from 44 to 74 years old, with an average age of $53.89 \pm 4.01$ years old). All patients enrolled were diagnosed with lung cancer by pathology and did not have other malignancies. The patients were diagnosed for the first time and did not receive radiotherapy, chemotherapy or immunotherapy. The tissues were stored at $-80^{\circ} \mathrm{C}$ prior to subsequent experiments. All human studies were approved by the Ethics Committee of Fourth Affiliated Hospital of Guangxi Medical University.

\section{Streptavidin-peroxidase (SP) staining}

SP staining (Bioss, USA) was performed to detect the ENTPD7 protein levels in lung tissues and adjacent tissues. Specimens were cut into $4-\mu \mathrm{m}$-thick section and deparaffinezed in xylene. $0.01 \mathrm{~mol} / \mathrm{L}$ citrate buffer solution was used for antigen retrieval and $50 \mu \mathrm{L}$ peroxidase blocking solution was added to block endogenous peroxidase activity. The primary antibody was added according to the instructions and incubated at $4{ }^{\circ} \mathrm{C}$ for $12 \mathrm{~h}$. The secondary antibody was added and incubated at room temperature for $10 \mathrm{~min}$. Next, $100 \mu \mathrm{L}$ DAB was added and held for $5 \mathrm{~min}$, hematoxylin was used for counterstaining, and the staining was observed under a microscope.

\section{Cell culture}

Human normal lung epithelial cell line (BEAS2B), lung adenocarcinoma cell line (A549), lung squamous cell carcinoma cell line (SK-MES-1), bronchioloalveolar carcinoma cell line (NCI-H1650), lung large cell cancer cell line (NCI-H1299) and lung giant cell cancer cell line (95-D) were purchased from American Type Culture Collection (Manassas, VA, USA) and cultured in RPMI 1640 or DMEM medium containing $10 \%$ fetal bovine serum (FBS) at $37^{\circ} \mathrm{C}$ in an incubator (Gibco, USA) with $5 \% \mathrm{CO}_{2}$.

\section{Cell transfection and grouping}

Plasmid transfection technology was applied to silence ENTPD7 gene, and the pGPU6/GFP/Neo plasmid vector containing small hairpin (sh)RNA targeting ENTPD7 was purchased from Origene (USA). Plasmid-shRNA-transfection of cells was performed using Lipofectamine 2000 (Invitrogen, CA) according to the instructions. Empty vector was used as negative control (NC) group. To explore the effect of ENTPD7 silencing on lung cancer cells, the cells were divided into control group (no transfection), vector group (cells transfected with pGPU6/GFP/NeoNC-shRNA) and sh-ENTPD7 group (cells transfected with pGPU6/GFP/Neo-ENTPD7-shRNA).

\section{Cell counting kit-8 (CCK-8) assay}

CCK-8 assay (Tongren, Japan) was performed to test the cell viability. Transfected cells $\left(100 \mathrm{~mL}, 3 \times 10^{3}\right.$ cells/ well) were inoculated in a 96-well plate and incubated at $37{ }^{\circ} \mathrm{C}$ with $5 \% \mathrm{CO}_{2}$ for 24,48 and $72 \mathrm{~h}$. CCK-8 reagent was then added into each well and cultured together at $37^{\circ} \mathrm{C}$ with $5 \% \mathrm{CO}_{2}$ for $4 \mathrm{~h}$. Optical density (OD) values at $450 \mathrm{~nm}$ were measured (ELX 800, Bio-Teck, USA).

\section{Crystal violet staining}

The crystal violet staining (Baomanbio, China) was used to test the cell proliferation ability.

\section{Flow cytometry}

Flow cytometry was used to detect cell apoptosis and the kits were purchased from BD Pharmingen (USA). $1 \times 10^{6}$ cells were washed with $\mathrm{PBS}$ at $4{ }^{\circ} \mathrm{C}$ and re-suspended to a concentration of $4 \times 10^{5}$ cells $/ \mathrm{mL}$. Propidium iodide (PI) and AnnexinV-FITC were added according to the instructions, and flow cytometer (FACSCalibur, Becton-Dickinson, USA) was used to detect the apoptosis rate.

\section{Mice modeling and sample collection}

BALB/c mice (6-8 weeks, 22 g-26g, SFP) were purchased from Laboratory Animal Center (China). Modeling and follow-up experimental programs had been approved by China Council on Animal Care. Twelve mice were randomly divided into 3 groups, which were control group $(n=4)$, vector group $(n=4)$ and sh-ENTPD7 group $(n=4)$. 
The A549 or SM-MES- 1 cells $\left(1 \times 10^{6}\right.$ each mouse $)$ were subcutaneously injected into the back of the mice, which were normally fed for 15 days. Ten $\mu$ g empty plasmid or $10 \mu \mathrm{g}$ sh-ENTPD7 plasmid was dissolved in saline and injected via the tail vein. Totally 5 injections should be carried out, and each injection was performed every 3 days for 15 days. The protein expression of ENTPD7 in different mice model groups were determined by Western blot. The tumors were surgically removed and measured.

\section{Western blot}

Proteins were determined using Western blot. Cells were lysed and supernatant was collected by centrifuging at $12000 \mathrm{rpm}$ at $4{ }^{\circ} \mathrm{C}$ for $15 \mathrm{~min}$. BCA assay was used to determine the protein concentration. SDS-PAGE gel was used in electrophoresis. PVDF membrane (Bio-Rad, USA) was transferred by a Trans-Blot Transfer Slot (Bio-Rad, USA) and blocked with 5\% fat-free milk for 2 $\mathrm{h}$ at room temperature. Primary antibodies (antiENTPD7, Abcam, ab236644, dilution: 1:700; anti-BAX, Abcam, ab32503, dilution: 1:700; anti-BCL2, Abcam, ab692, dilution: 1:800; anti-CDKN2A, Abcam, ab51243, dilution: 1:800; anti-CIP1, Abcam, ab109199, dilution: 1: 900; anti-P53, Abcam, ab26, dilution: 1:800; anti-MKI67, Abcam, ab92742, dilution: 1:800; anti-Ras, Abcam, ab52939, dilution: 1:600; anti-Raf-1, Abcam, ab137435, dilution: 1:700; anti-MEK, Abcam, ab178876, dilution: 1: 700; anti-p-MEK, Abcam, ab194754, dilution: 1:700; anti-ERK, Abcam, ab54230, dilution: 1:800; anti-p-ERK, Abcam, ab65142, dilution: 1:800; anti-GAPDH, Abcam, ab8245, $36 \mathrm{kDa}$, dilution: 1:800) were added according to the instruction, and the samples were shaken at room temperature for $2 \mathrm{~h}$ and incubated at $4{ }^{\circ} \mathrm{C}$ for $12 \mathrm{~h}$. Secondary antibodies (mouse anti-human IgG, Abcam, ab1927, dilution: 1:10000; rabbit anti-human IgG, Abcam, ab6759, dilution: 1:8000; rabbit anti-goat IgG, Abcam, ab6741, dilution: 1:10000; donkey anti-rabbit IgG, R\&D, NL004, 1:5000; goat anti-mouse IgG, Abcam, ab6785, 1:8000;) were added and incubated at room temperature for $1.5 \mathrm{~h}$. Chemiluminescence detection was carried out using ECL reagent (Huiying, Shanghai, China). All protein assays were performed in triplicate.

Quantitative real-time polymerase chain reaction (qRT-PCR) The expression levels of mRNA were determined by qRT-PCR. The cells were triturated and lysed, and RNA from the cells was extracted by RNA extraction kit (Promega, Beijing, China). Reverse transcription kit (TaKaRa, Japan) was used to synthesize cDNA. Reverse transcription reaction condition was set at $37^{\circ} \mathrm{C}$ for $15 \mathrm{~min}$, while reverse transcriptase inactivation condition was set at $85^{\circ} \mathrm{C}$ for $15 \mathrm{~s}$. qRT-PCR was performed with the qRT-PCR kit (TaKaRa, Japan). PCR was performed by activating DNA polymerase at $95^{\circ} \mathrm{C}$ for $5 \mathrm{~min}$, followed by 40 cycles of two-step PCR (at $95^{\circ} \mathrm{C}$ for $10 \mathrm{~s}$ and at $60^{\circ} \mathrm{C}$ for $30 \mathrm{~s}$ ) and a final extension at $75^{\circ} \mathrm{C}$ for $10 \mathrm{~min}$ and held at $4{ }^{\circ} \mathrm{C}$. RNase-free water was used as the templates of negative control. All primers were obtained from Genewiz (Suzhou, Jiangsu China) and listed in Table 1. $2^{-\Delta \Delta C T}$ was used to analyze the mRNA expression level, and the data were represented by $\Delta \Delta \mathrm{Ct}$. All PCR reactions were performed in triplicate. GAPDH was used as an internal control, and the mRNA expression of each gene was normalized against GAPDH expression.

\section{Statistical analysis}

All the experimental data were presented as mean \pm standard deviation (SD). Statistical analysis was performed by SPSS 20 (SPSS, Inc., Chicago, IL, USA). Differences among the experimental groups were analyzed by One-way analysis of variance (ANOVA) followed by Turkey's multiple comparison. Statistical significance was defined as $P<0.05$.

\section{Results \\ ENTPD7 was overexpressed in lung cancer}

A total of 496 cases (270 cases of stage I, 119 cases of stage II patients, 81 cases of stage III patients, and 26 cases of stage IV) of lung cancer were downloaded from the TCGA. The analysis showed that the mRNA expression levels of ENTPD7 were different in tumor tissues of patients at different TNM stages (Fig. 1a). Further survival analysis also showed that patients with a low level of ENTPD7 had a higher survival rate than patients with a high ENTPD7 level (Fig. 1b). SP staining results also showed that ENTPD7 had

Table 1 The sequences of primers

\begin{tabular}{|c|c|c|}
\hline Primer name & Sequence $\left(5^{\prime}-3^{\prime}\right)$ & $\begin{array}{l}\text { Product } \\
\text { size (bp) }\end{array}$ \\
\hline ENTPD7-forward & CCCCTITACATCCTCTGCAC & \\
\hline ENTPD7-reverse & GTCAAACTCCAACGGCAAAT & 242 \\
\hline BAX-Forward & TCCACCAAGAAGCTGAGCGAG & \\
\hline BAX-Reverse & TTCTITGAGTTCGGTGGGGTC & 188 \\
\hline$B C L 2$-Forward & CTGGTGGACAACATCGC & \\
\hline BCL2-Reverse & GGAGAAATCAAACAGAGGC & 164 \\
\hline CDKN2A-Forward & GTGCTCACTCCAGAAAACTC & \\
\hline CDKN2A -Reverse & AATGTCCTGCCTITAACGTAG & 147 \\
\hline CIP1-Forward & AGTATGCCGTCGTCTGTTCG & \\
\hline CIP1-Reverse & CTTGTCCCCCTCCCAGGTCA & 178 \\
\hline P53-Forward & CTGAGGTCGGCTCCGACTATACCACTATCC & \\
\hline P53-Reverse & CTGATTCAGCTCTCGGAACATCTCGAAGCG & 260 \\
\hline MKI67-Forward & GCAGGACTTCACTTGCTTCC & \\
\hline MKI67-Reverse & TCATTTGCGTTTGTTCACG & 144 \\
\hline GAPDH-Forward & CCATCTTCCAGGAGCGAGAT & \\
\hline GAPDH-Reverse & TGCTGATGATCTTGAGGCTG & 222 \\
\hline
\end{tabular}




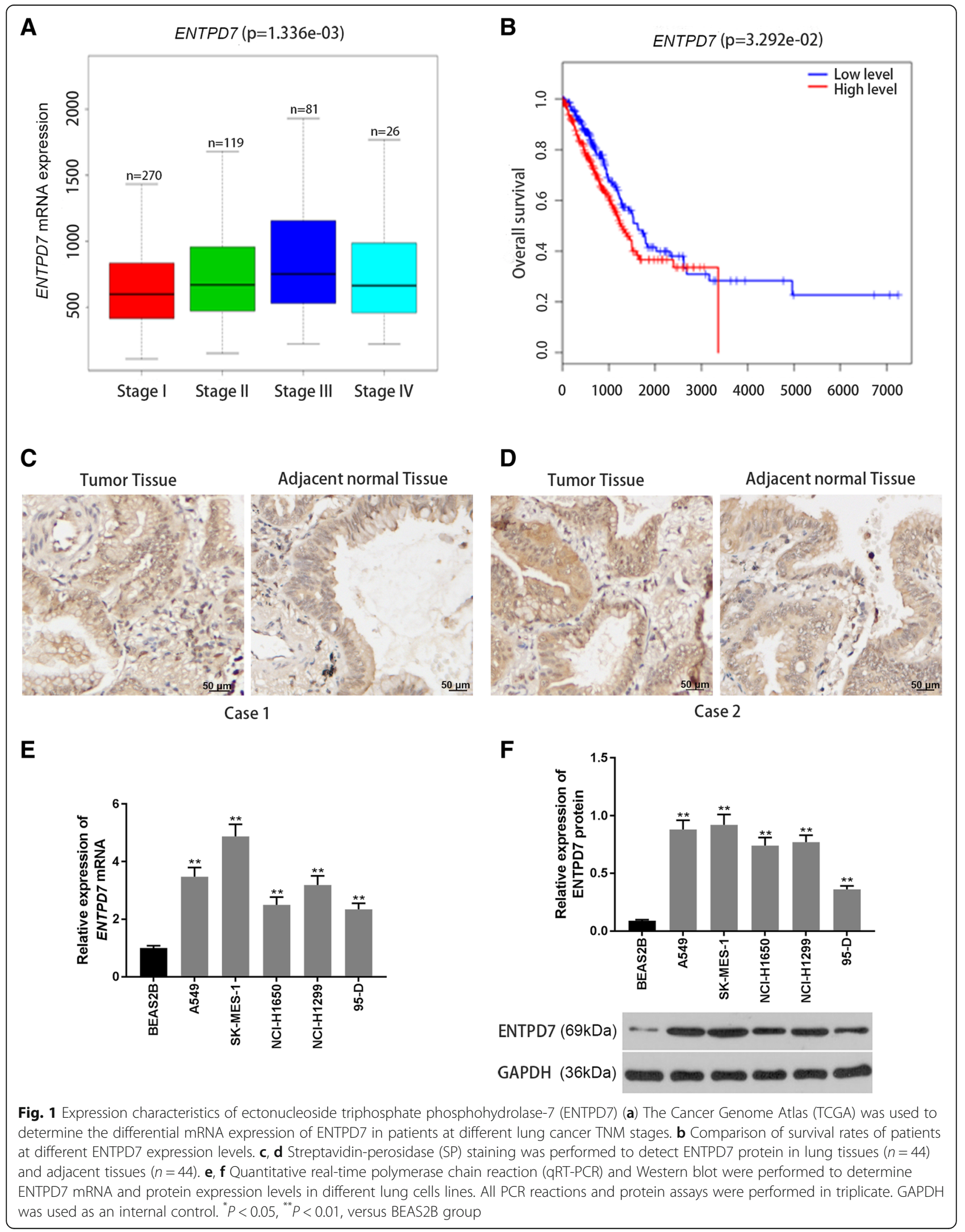




\section{A549}

A

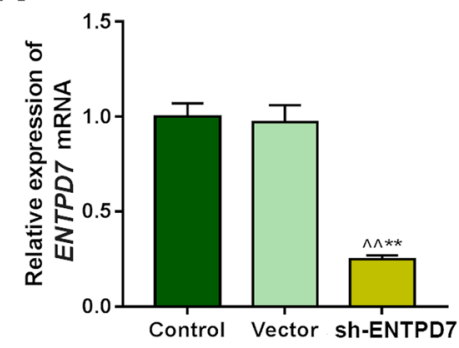

B

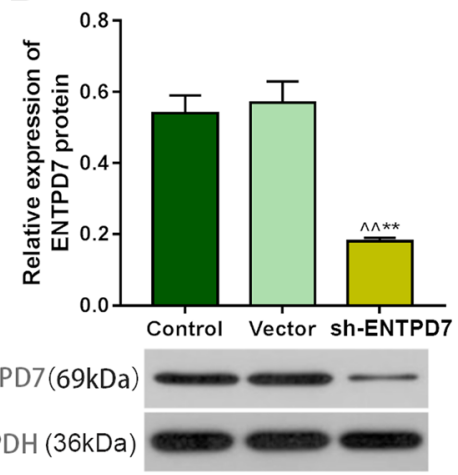

C

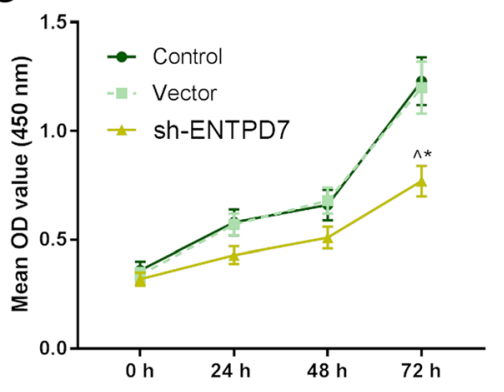

D

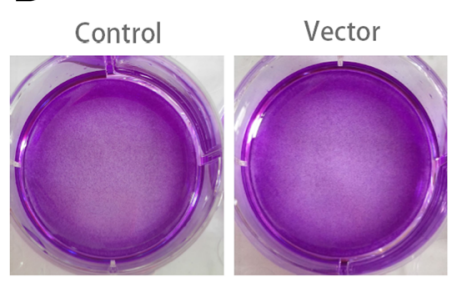

E

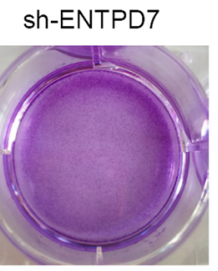

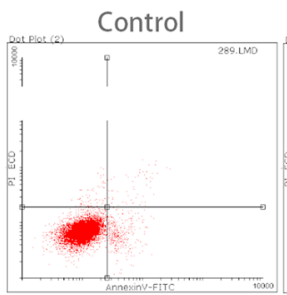

$R B+R T=4.06$

$\mathrm{LB}+\mathrm{LT}=95.94$

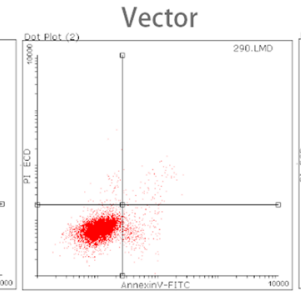

$\mathrm{RB}+\mathrm{RT}=4.98$

$\mathrm{LB}+\mathrm{LT}=95.02$

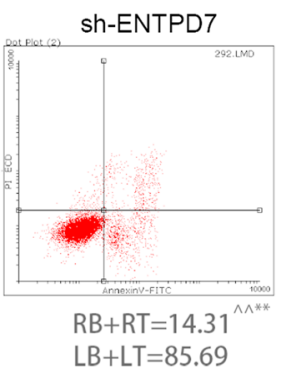

\section{SM-MES-1}
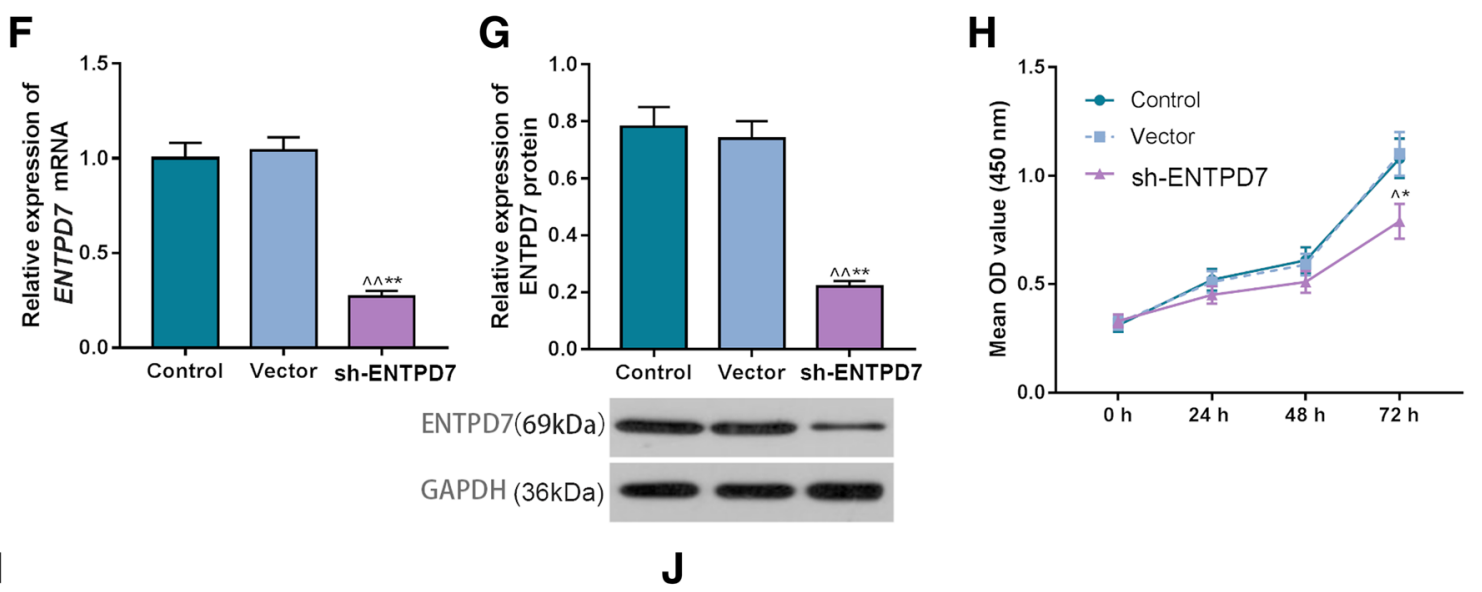

I

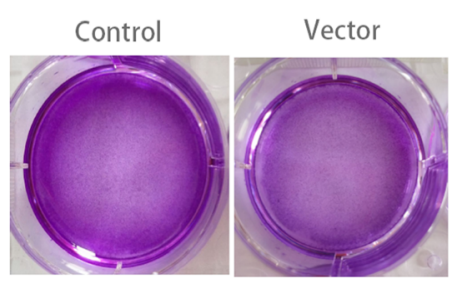

sh-ENTPD7

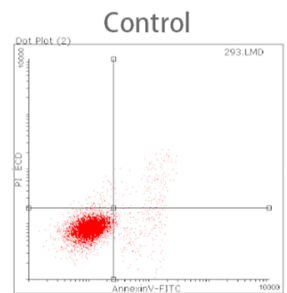

$R B+R T=4.60$

$\mathrm{LB}+\mathrm{LT}=95.40$

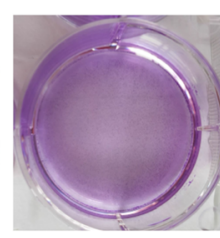

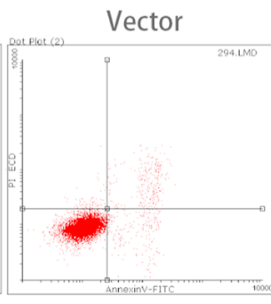

$\mathrm{RB}+\mathrm{RT}=5.54$

$\mathrm{LB}+\mathrm{LT}=94.46$

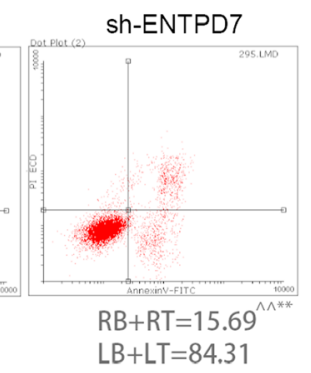

Fig. 2 (See legend on next page.) 
(See figure on previous page.)

Fig. 2 Effects of ectonucleoside triphosphate phosphohydrolase-7 (ENTPD7) silencing on A549 and SM-MES-1 cells. a, b, f, g ENTPD7 mRNA and protein expression levels were detected by quantitative real-time polymerase chain reaction (qRT-PCR) and Western blot. GAPDH was used as an internal control. All PCR reactions and protein assays were performed in triplicate. $\mathbf{c}$, $\mathbf{h}$ Cell counting kit-8 (CCK-8) assay was performed to tested cell viability. $\mathbf{d}$, $\mathbf{i}$ The crystal violet staining was used to test the cell proliferation ability. Pale violet staining represented a low proliferation, and dark violet staining meant high proliferation. $\mathbf{e}, \mathbf{j}$ Apoptosis rates were detected using flow cytometry. A549 and SM-MES-1 cells were stained with Annexin V-FITC and PI. ${ }^{\wedge} P<0.05,{ }^{\wedge} P<0.01$, versus control group; ${ }^{*} P<0.05$, ${ }^{* *} P<0.01$, versus vector group

a higher expression level in lung cancer tissues than that in adjacent tissues (Fig. 1c, d).

The expression level of ENTPD7 in different lung cancer cell lines was detected by qRT-PCR and Western blot. The results showed that the expression levels of ENTPD7 mRNA and protein in A549, SK-MES-1, NCIH1650, NCI-H1299 and 95-D cell lines were significantly higher than those in human normal lung epithelial cell line BEAS2B, and among them, ENTPD7 expression was the highest in A549 and SK-MES-1 cells (Fig. 1e, f). This suggested that the ENTPD7 gene was up-regulated in lung cancer tissues and cells.

\section{Effects of ENTPD7 silencing on A549 cells and SK-MES-1 cells}

Western blot and qRT-PCR results showed that ENTPD7 protein and mRNA levels in the sh-ENTPD7 group were significantly lower than those in the control group, vector group of A549 cells and SM-MES-1 cells (Fig. 2a, b, f, g), suggesting that plasmid transfection successfully down-regulated the expression of ENTPD7. OD value in the shENTPD7 group was greatly lower than that in the control group and vector group, while apoptotic rate in shENTPD7 group was noticeably higher than that in the control group and vector group (Fig. 2c-e, h-j). This indicated that a low expression of ENTPD7 inhibited the proliferation but promoted apoptosis of A549 cells and SM-MES-1 cells.

\section{Effects of ENTPD7 silencing on proliferation and apoptosis}

To further investigate the effects of ENTPD7 on proliferation and apoptosis, the levels of cell cycle-associated and apoptosis-related proteins in the three groups of two cell lines were determined. The results showed that the protein expression levels of BAX, CIP1 and P53 were up-regulated in the sh-ENTPD7 group of A549 cells and SM-MES-1 cells, the expression level of CDKN2A was also increased in the sh-ENTPD7 group of SM-MES-1 cells, however, the expression levels of BCL2 and MKI67 levels were down-regulated in the sh-ENTPD7 group (Fig. 3a-f). Our data demonstrated that down-regulation of ENTPD7 regulated the proliferation and apoptosis of lung cancer cells by modulating cell cycle-associated and apoptosis-related proteins.
Effects of ENTPD7 silencing on Ras/Raf/MEK/ERK pathway To explore the mechanism by which ENTPD7 affects cell proliferation and apoptosis, the expression levels of proteins in the Ras/Raf/MEK/ERK pathway in the three groups of two cell lines were detected. The results show that in both cell lines, Ras, Raf protein expression levels and phosphorylation levels of MEK and ERK proteins in the sh-ENTPD7 group were significantly lower than those in the control group and vector group (Fig. 4a-j). This suggested that ENTPD7 with a low expression inhibited Ras/Raf/MEK/ERK pathway.

\section{Effects of ENTPD7 silencing on lung tumor in vivo}

The results showed that the expression level of ENTPD7 in sh-ENTPD7 group was significantly lower than that in the control group and vector group, and the tumor volume and weight in the sh-ENTPD7 group were greatly smaller than those in the control group and vector group (Fig. 5a-j), showing that the sh-ENTPD7 plasmid had an inhibitory effect on lung tumor.

\section{Discussion}

Nucleotides have different functions in cells. Studies have shown that nucleotides play an important role in cell metabolism, proliferation and apoptosis, thus, the level of ATP is tightly regulated [18-20]. The levels of extracytoplasmic (extracellular and intraorganellar) nucleotides are modulated by the degradative activity of ENTPDs [21, 22]. Research has found that ENTPDs were also associated with cancer, as ENTPD5 affected the proliferation of liver cancer cells [23]. Moreover, by conducting bioinformatics research, we found that ENTPD7 levels in lung cancer patients at different TNM stages were different, and the survival analysis showed that lung cancer patients with a low level of ENTPD7 had a higher survival rate. Therefore, ENTPD7 was selected to be used in the further research.

We first determined the expression characteristics of ENTPD7 in lung cancer tissues by using clinical samples. SP staining results showed that the expression level of ENTPD7 in lung cancer tissues was higher than that in adjacent tissues. Furthermore, the results also showed that the mRNA and protein levels of ENTPD7 in the five lung cancer cell lines were significantly higher than those in normal lung epithelial cells, showing that ENTPD7 was overexpressed in lung cancer tissues and cells. To further 


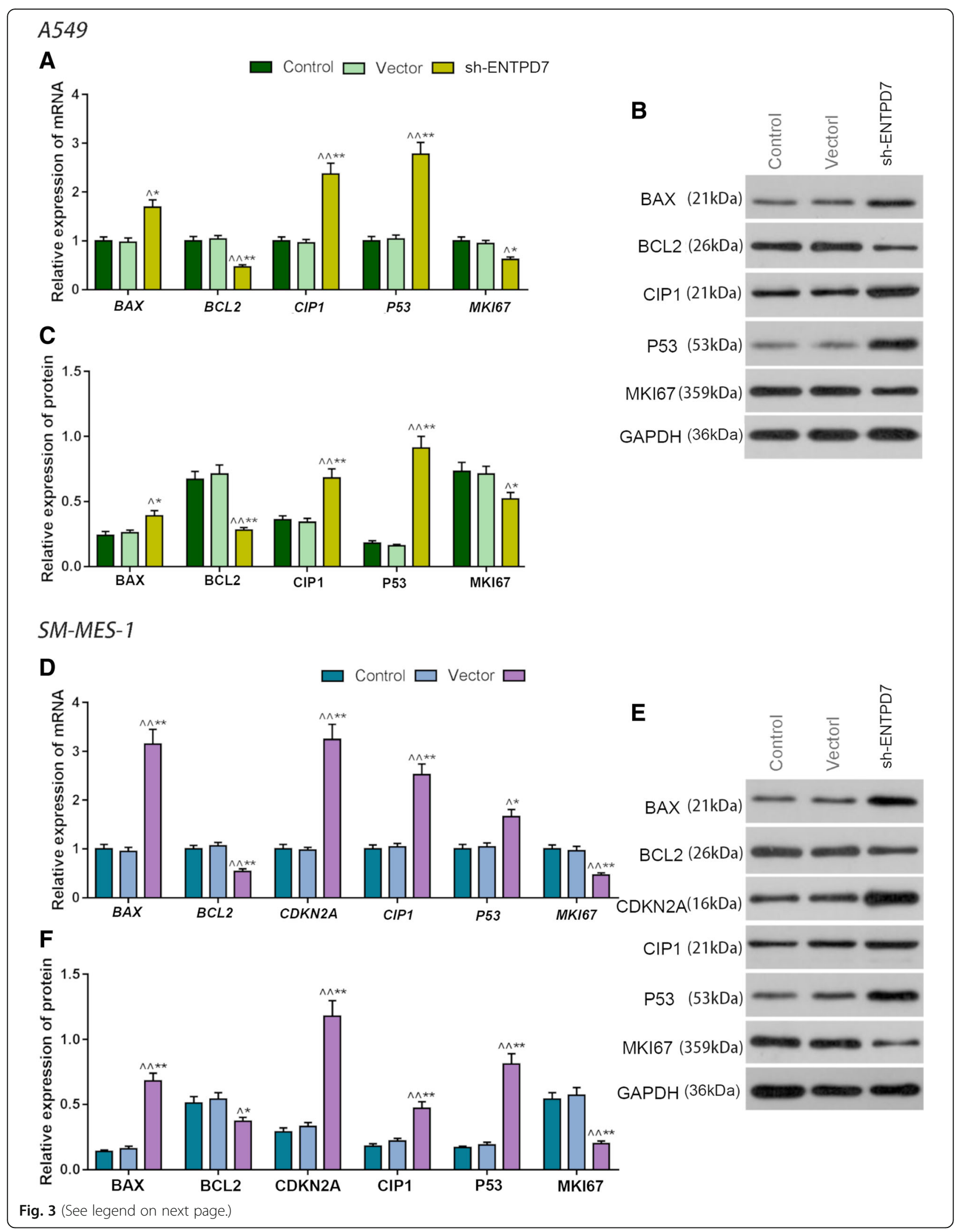


(See figure on previous page.)

Fig. 3 Effects of ectonucleoside triphosphate phosphohydrolase-7 (ENTPD7) silencing on proliferation and apoptosis. a-f Quantitative real-time polymerase chain reaction (qRT-PCR) and Western blot were performed to detect the protein and mRNAs levels of BAX, BCL2, CDKN2A, CIP1, P53 and MKI67. All PCR reactions and protein assays were performed in triplicate. GAPDH was used as an internal control. ${ }^{\wedge} P<0.05,{ }^{\wedge} P<0.01$, versus control group; ${ }^{*} P<0.05,{ }^{* *} P<0.01$, versus vector group

investigate the effects of ENTPD7 gene on lung cancer cells, A549 and SK-MES-1 cells with high ENTPD7 expression were selected as subjects, and ENTPD7 was silenced by plasmid transfection. The results showed that the down-regulation of ENTPD7 expression inhibited the proliferation but promoted apoptosis of A549 and SKMES- 1 cells.

In order to study the mechanism underlying the inhibition of ENTPD7 on lung cancer cells, we reviewed previous research, though only a few papers focused on the direct effect of ENTPD7 on tumor cell apoptosis or proliferation, ENTPD7, as an enzyme that regulates nucleotide levels, was shown to have a function of modulating ATP, which in turn regulates the transduction of signals for phosphorylation of proteins in signaling pathways [24, 25].

Abnormality of cell proliferation or apoptosis caused by mutation or activation of receptor tyrosine kinase (RTK) and its related pathways is one of the characteristics of tumors [26]. The up-regulation of Ras/Raf/MEK/ERK pathway promotes cell proliferation, and inhibits apoptosis $[27,28]$ and cell senescence [29-31]. Studies have shown that down-regulation of Ras/Raf/MEK/ERK and p16INK4A/Rb signaling attenuates tumor cell senescence induced by baicalin [32]. Peng [33] also showed that in NSCLC, the inhibition of senescence caused by Raf mutation is involved in the development of lung cancer. Cellular senescence, which refers to the irreversible cell cycle arrest of cells, can inhibit the proliferation of cells, thus, inducing cell senescence is an important method in tumor therapy [34]. Replicative senescence (RS) caused by telomere shortening [35], oncogene-induced senescence (OIS) caused by oncogenes activation such as RAS or B-Raf ${ }^{\mathrm{V} 600 \mathrm{E}}$ [36], PTEN-loss induced cellular senescence (PICS) [37] and stress-induced senescence [38] are currently triggered cell senescence. After the senescence signal is triggered, senescence-related proteins such as p16, p21 and p53 are activated and could cause cell senescence $[39,40]$. p53p21 and p16-Rb tumor suppressor pathways are pathways for cellular senescence, and Ras-induced senescent cells are often associated with the up-regulation of p16, p53 and p21 [41, 42]. It is currently believed that Ras mainly relies on the RAF/MEK/ERK pathway in regulating key proteins such as p14/p19, p53 and p16 expression and causing cell senescence [43]. Once Ras is activated, the downstream RAF is recruited to the cell membrane and activated. RAF subsequently phosphorylates MEK, which phosphorylates and activates the extracellular regulatory protein to over-activate ERK1/2, therefore leading to the accumulation of intracellular oxygen free radicals, causing DNA damage response and cell senescence [44-46].

The results of this study showed that silencing ENTPD7 up-regulated the levels of CDKN2A, CIP1 and P53 but down-regulated the expression level of MKI67. P16 (CDKN2A), p21 (CIP1) and p53 (P53) are not only the main senescence -associated proteins, but also important markers of cell cycle. Tordella et al. found that ENTPD7 expression induced several senescent effectors in liver cancer cell including p16INK4a, p53 and p21 [17]. Same gene showing different mechanisms in different tumor may be related to the type of tumor cells, living environment or other factors. Tumors are heterogeneous populations of cells, and the intra-tumor heterogeneity further enhances the effect of clone variation and microenvironment on cancer cells [47]. Heterogeneity of tumor and microenvironment allow a gene to have different functions and effects on different tumor cell lines, however, such a functional difference still needs to be further confirmed. As a tumor suppressor gene, p53 could inhibit cell proliferation by arresting the cell cycle [48], while p21 gene act as a cyclin-dependent kinase inhibitor downstream of p53 gene [49]. P21 can form a cell cycle G1 checkpoint with p53 [50]. Ki67 (MKI67) is a non-histone in the nucleus and is expressed in every cell cycle. However, when $M$ phase is completed, Ki67 will degrade rapidly, thus, cells in the G0 phase do not express ki67 [51, 52]. In addition, the results also showed that the protein expression levels of Ras, Raf and phosphorylation levels of MEK and ERK proteins were significantly down-regulated after down-regulating ENTPD7, suggesting that ENTPD7 could promote the expressions of p21 and p53 by inhibiting the expression and activation of Ras/Raf/ MEK/ERK pathway, thereby inducing cell senescence, arresting cells in G0 phase and finally inhibiting cell proliferation. In addition, Ras/Raf/MEK/ERK pathway also has an effect of promoting apoptosis, and the result experiment also showed that inhibiting ENTPD7 could promote the expression of pro-apoptotic protein Bax and inhibit the level of anti-apoptotic protein Bcl-2 [53, 54]. This demonstrated that the inhibition of ENTPD7 might inhibit lung cancer cell proliferation and promote apoptosis by down-regulating protein expression and phosphorylation of the protein in the Ras/Raf/MEK/ERK pathway. Further animal experiments in vivo have also shown that the intravenous administration of sh-ENTPD7 plasmid had an effect of inhibiting the growth of lung cancer cells. 


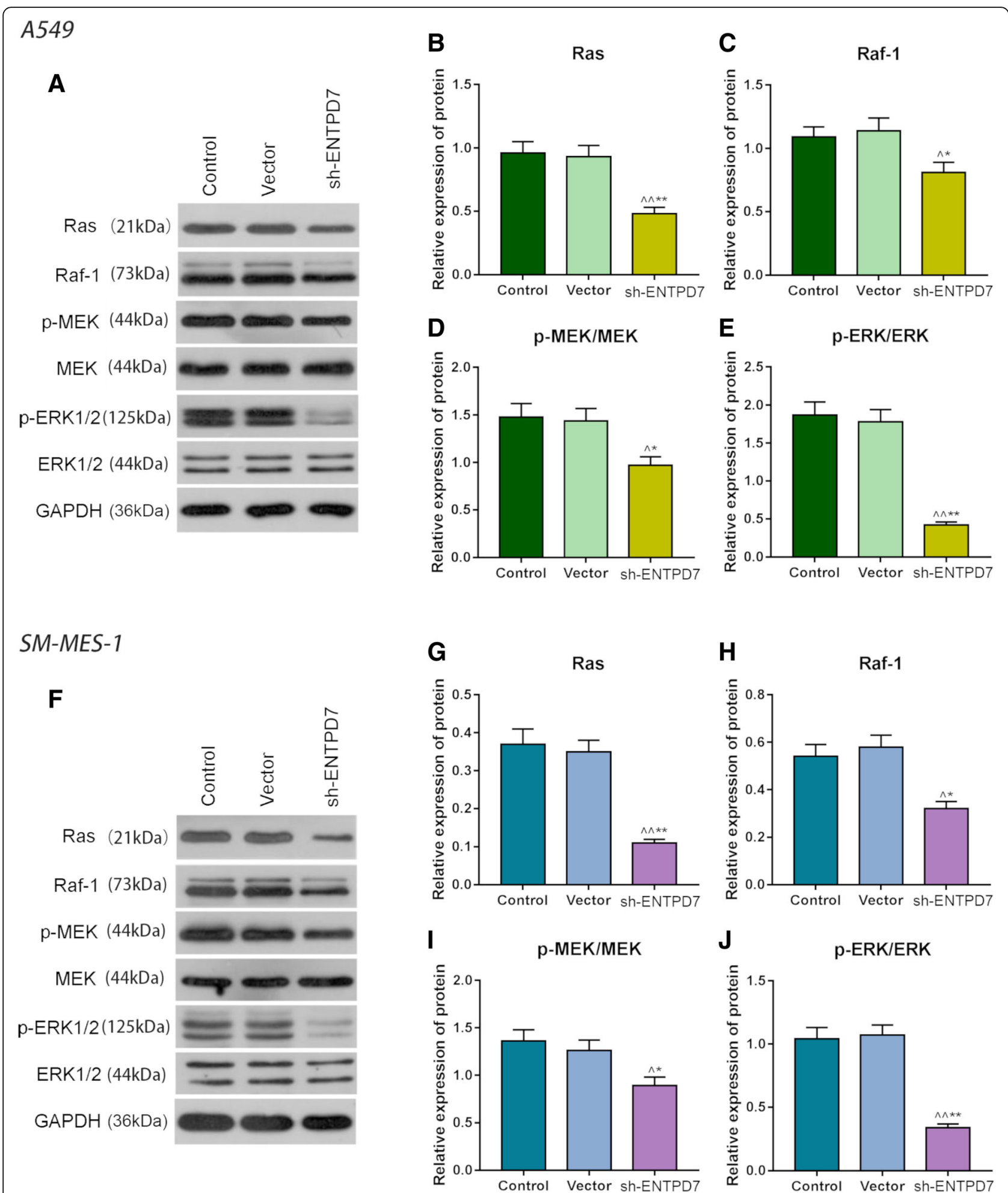

Fig. 4 Effects of ENTPD7 silencing on Ras/Raf/MEK/ERK pathway. a-j Western blot was used to detect Ras and Raf proteins levels and phosphorylation levels of MEK and ERK protein in A549 and SM-MES-1 cells. All PCR reactions and protein assays were performed in triplicate. GAPDH was used as an internal control. ${ }^{\wedge} P<0.05,{ }^{\wedge \wedge} P<0.01$, versus control group; ${ }^{*} P<0.05,{ }^{* *} P<0.01$, versus vector group 


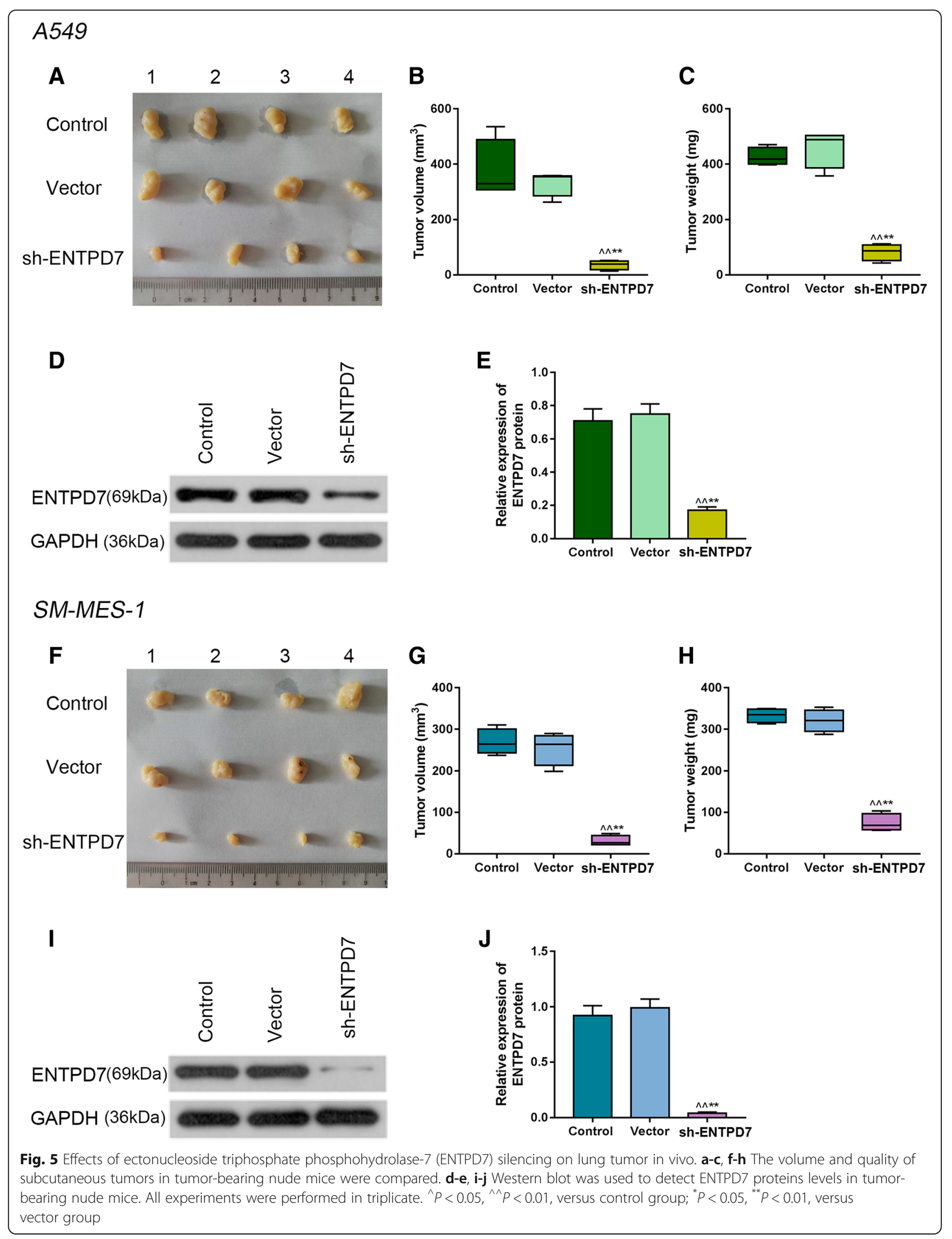




\section{Conclusions}

In conclusion, ENTPD7 was overexpressed in lung cancer tissues and cells, and the inhibition of ENTPD7 had the effects of inhibiting lung cancer cell proliferation and promoting apoptosis of lung cancer cells, and this might be related to the inhibition of Ras/Raf/MEK/ERK induced by ENTPD7.

\section{Abbreviations}

ANOVA: Analysis of variance; ENTPD7: Ectonucleoside triphosphate phosphohydrolase-7; ENTPDase: Ecto-nucleoside triphosphate diphosphohydrolase; ERK: Extracellular signal-regulated kinase; MEK: Mitogenactivated protein kinase; NSCLC: Non-small cell lung cancer; OD: Optical density; OIS: Oncogene-induced senescence; PICS: PTEN-loss induced cellular senescence; RS: Replicative senescence; RTK: Receptor tyrosine kinase; SCLC: Small cell lung cancer; SD: Standard deviation; SP: Streptavidinperoxidase; TCGA: The Cancer Genome Atlas; TKl: Tyrosine kinase inhibitors; TNM: Tumor node metastasis; WGCNA: Weighted gene co-expression network analysis

\section{Acknowledgements}

Not applicable.

\section{Authors' contributions}

Substantial contributions to conception and design: ZW, YH. Data acquisition, data analysis and interpretation: RJ, ZW. Drafting the article or critically revising it for important intellectual content: DR, XL. Final approval of the version to be published: All authors. Agreement to be accountable for all aspects of the work in ensuring that questions related to the accuracy or integrity of the work are appropriately investigated and resolved: ZW, ZL.

\section{Funding}

Not applicable.

\section{Availability of data and materials}

The analyzed data sets generated during the study are available from the corresponding author on reasonable request.

\section{Ethics approval and consent to participate}

All procedures performed in studies involving human participants were in accordance with the ethical standards of the institutional and/or national research committee and with the 1964 Helsinki declaration and its later amendments or comparable ethical standards.

\section{Consent for publication}

Not applicable.

\section{Competing interests}

The authors declare that they have no competing interests.

Received: 26 December 2018 Accepted: 13 August 2019

Published online: 23 August 2019

\section{References}

1. Ferlay J, Soerjomataram I, Dikshit R, Eser S, Mathers C, Rebelo M, Parkin DM, Forman D, Bray F. Cancer incidence and mortality worldwide: sources, methods and major patterns in GLOBOCAN 2012. Int J Cancer. 2015;136: E359-86.

2. Wender R, Fontham ET, Barrera E Jr, Colditz GA, Church TR, Ettinger DS, Etzioni R, Flowers CR, Gazelle GS, Kelsey DK, et al. American Cancer Society lung cancer screening guidelines. CA Cancer J Clin. 2013;63:107-17.

3. Li X, Zhang Q, Fan K, Li B, Li H, Qi H, Guo J, Cao Y, Sun H. Overexpression of TRPV3 correlates with tumor progression in non-small cell lung cancer. Int J Mol Sci. 2016:17:437.

4. Garon EB, Rizvi NA, Hui R, Leighl N, Balmanoukian AS, Eder JP, Patnaik A, Aggarwal C, Gubens M, Horn L, et al. Pembrolizumab for the treatment of non-small-cell lung cancer. N Engl J Med. 2015;372:2018-28.
5. Nojiri T, Hamasaki T, Inoue M, Shintani Y, Takeuchi Y, Maeda H, Okumura M. Long-term impact of postoperative complications on cancer recurrence following lung cancer surgery. Ann Surg Oncol. 2017;24:1135-42.

6. Park BJ, Melfi F, Mussi A, Maisonneuve P, Spaggiari L, Da Silva RK, Veronesi G. Robotic lobectomy for non-small cell lung cancer (NSCLC): long-term oncologic results. J Thorac Cardiovasc Surg. 2012;143:383-9.

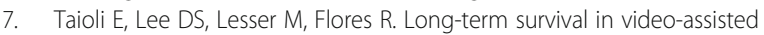
thoracoscopic lobectomy vs open lobectomy in lung-cancer patients: a meta-analysis. Eur J Cardiothorac Surg. 2013;44:591-7.

8. Chen MJ, Zhong W, Zhang L, Zhao J, Li LY, Wang MZ. Recurrence patterns of advanced non-small cell lung cancer treated with gefitinib. Chin Med J. 2013;126:2235-41.

9. Chang F, Steelman LS, Shelton JG, Lee JT, Navolanic PM, Blalock WL, Franklin R, McCubrey JA. Regulation of cell cycle progression and apoptosis by the Ras/Raf/MEK/ERK pathway (review). Int J Oncol. 2003:22:469-80.

10. Ritt DA, Abreu-Blanco MT, Bindu L, Durrant DE, Zhou M, Specht SI, Stephen AG, Holderfield M, Morrison DK. Inhibition of Ras/Raf/MEK/ERK pathway signaling by a stress-induced Phospho-regulatory circuit. Mol Cell. 2016;64: 875-87.

11. Kim YH, Choi YW, Han JH, Lee J, Soh EY, Park SH, Kim JH, Park TJ. TSH signaling overcomes B-RafV600E-induced senescence in papillary thyroid carcinogenesis through regulation of DUSP6. Neoplasia. 2014;16:1107-20.

12. Henriques AF, Barros P, Moyer MP, Matos P, Jordan P. Expression of tumorrelated Rac1b antagonizes B-Raf-induced senescence in colorectal cells. Cancer Lett. 2015;369:368-75.

13. Jacob K, Quang-Khuong DA, Jones DT, Witt H, Lambert S, Albrecht S, Witt O, Vezina C, Shirinian M, Faury D, et al. Genetic aberrations leading to MAPK pathway activation mediate oncogene-induced senescence in sporadic pilocytic astrocytomas. Clin Cancer Res. 2011;17:4650-60

14. Herbig U, Ferreira M, Condel L, Carey D, Sedivy JM. Cellular senescence in aging primates. Science. 2006;311:1257.

15. Weiner-Gorzel K, Dempsey E, Milewska M, McGoldrick A, Toh V, Walsh A Lindsay S, Gubbins L, Cannon A, Sharpe D, et al. Overexpression of the microRNA miR-433 promotes resistance to paclitaxel through the induction of cellular senescence in ovarian cancer cells. Cancer Med. 2015;4:745-58.

16. Robson SC, Sevigny J, Zimmermann H. The E-NTPDase family of ectonucleotidases: structure function relationships and pathophysiological significance. Purinergic Signal. 2006;2:409-30.

17. Tordella L, Khan S, Hohmeyer A, Banito A, Klotz S, Raguz S, Martin N, Dhamarlingam G, Carroll T, Gonzalez Meljem JM, et al. SWI/SNF regulates a transcriptional program that induces senescence to prevent liver cancer. Genes Dev. 2016;30:2187-98.

18. Hatori M, Teixeira CC, Debolt K, Pacifici M, Shapiro IM. Adenine nucleotide metabolism by chondrocytes in vitro: role of ATP in chondrocyte maturation and matrix mineralization. J Cell Physiol. 1995;165:468-74.

19. Tanaka M, Lee K, Martinez-Augustin O, He Y, Sanderson IR, Walker WA Exogenous nucleotides alter the proliferation, differentiation and apoptosis of human small intestinal epithelium. J Nutr. 1996;126:424-33.

20. Hester S: Individual and combined effects of nucleotides and human Milk oligosaccharides on proliferation, apoptosis and necrosis in a human fetal intestinal cell line. 2012.

21. Junger WG. Immune cell regulation by autocrine purinergic signalling. Nat Rev Immunol. 2011:11:201-12.

22. Doleski PH, Mendes RE, Leal DB, Bottari NB, Piva MM, Da Silva ES, Gabriel ME, Lucca NJ, Schwertz Cl, Giacomim P, et al. Seric and hepatic NTPDase and 5' nucleotidase activities of rats experimentally infected by Fasciola hepatica. Parasitology. 2016;143:551-6.

23. Read R, Hansen G, Kramer J, Finch R, Li L, Vogel P. Ectonucleoside triphosphate diphosphohydrolase type 5 (Entpd5)-deficient mice develop progressive hepatopathy, hepatocellular tumors, and spermatogenic arrest. Vet Pathol. 2009;46:491-504.

24. Aldi S, Marino A, Tomita K, Corti F, Anand R, Olson KE, Marcus AJ, Levi R. ENTPDase1/CD39 modulates renin release from heart mast cells during ischemia/reperfusion: a novel cardioprotective role. FASEB J. 2015:29:61-9.

25. Jackson EK, Cheng D, Jackson TC, Verrier JD, Gillespie DG. Extracellular guanosine regulates extracellular adenosine levels. Am J Physiol Cell Physiol. 2013;304:C406-21

26. Hallberg $\mathrm{B}$, Palmer $\mathrm{RH}$. Mechanistic insight into ALK receptor tyrosine kinase in human cancer biology. Nat Rev Cancer. 2013;13:685-700.

27. Zhang Q, Wei L, Yang H, Yang W, Yang Q, Zhang Z, Wu K, Wu J. Bromodomain containing protein represses the Ras/Raf/MEK/ERK pathway 
to attenuate human hepatoma cell proliferation during HCV infection. Cancer Lett. 2016:371:107-16.

28. Dumaz N, Marais R. Integrating signals between CAMP and the RAS/RAF/MEK ERK signalling pathways. Based on the anniversary prize of the Gesellschaft fur Biochemie und Molekularbiologie lecture delivered on 5 July 2003 at the special FEBS meeting in Brussels. FEBS J. 2005;272:3491-504.

29. Tabibian JH, O'Hara SP, Splinter PL, Trussoni CE, LaRusso NF. Cholangiocyte senescence by way of $\mathrm{N}$-ras activation is a characteristic of primary sclerosing cholangitis. Hepatology. 2014;59:2263-75.

30. Scurr LL, Pupo GM, Becker TM, Lai K, Schrama D, Haferkamp S, Irvine M, Scolyer RA, Mann GJ, Becker JC, et al. IGFBP7 is not required for B-RAFinduced melanocyte senescence. Cell. 2010;141:717-27.

31. Tabor V, Bocci M, Alikhani N, Kuiper R, Larsson LG. MYC synergizes with activated BRAFV600E in mouse lung tumor development by suppressing senescence. Cancer Res. 2014;74:4222-9.

32. Lin TY, Cheng YC, Yang HC, Lin WC, Wang CC, Lai PL, Shieh SY. Loss of the candidate tumor suppressor BTG3 triggers acute cellular senescence via the ERK-JMJD3-p16(INK4a) signaling axis. Oncogene. 2012;31:3287-97.

33. Peng S, Sen B, Mazumdar T, Byers LA, Diao L, Wang J, Tong P, Giri U, Heymach JV, Kadara HN, Johnson FM. Dasatinib induces DNA damage and activates DNA repair pathways leading to senescence in non-small cell lung cancer cell lines with kinase-inactivating BRAF mutations. Oncotarget. 2016; 7:565-79.

34. Munoz-Espin D, Canamero M, Maraver A, Gomez-Lopez G, Contreras J, Murillo-Cuesta S, Rodriguez-Baeza A, Varela-Nieto I, Ruberte J, Collado M, Serrano M. Programmed cell senescence during mammalian embryonic development. Cell. 2013;155:1104-18.

35. Petrova NV, Velichko AK, Razin SV, Kantidze OL. Small molecule compounds that induce cellular senescence. Aging Cell. 2016;15(6):999-1017.

36. Xie X, Koh JY, Price S, White E, Mehnert JM. Atg7 overcomes senescence and promotes growth of BrafV600E-driven melanoma. Cancer Discov. 2015; 5:410-23.

37. Tan W, Gu Z, Shen B, Jiang J, Meng Y, Da Z, Liu H, Tao T, Cheng C. PTEN/ Akt-p27(kip1) signaling promote the BM-MSCs senescence and apoptosis in SLE patients. J Cell Biochem. 2015;116:1583-94.

38. Ogrunc M, Di Micco R, Liontos M, Bombardelli L, Mione M, Fumagalli M. Gorgoulis VG, d'Adda di Fagagna F: oncogene-induced reactive oxygen species fuel hyperproliferation and DNA damage response activation. Cell Death Differ. 2014;21:998-1012.

39. Herbig U, Jobling WA, Chen BP, Chen DJ, Sedivy JM. Telomere shortening triggers senescence of human cells through a pathway involving ATM, p53, and p21(CIP1), but not p16(INK4a). Mol Cell. 2004;14:501-13.

40. Yang F, Yi M, Liu Y, Wang Q, Hu Y, Deng H. Glutaredoxin-1 silencing induces cell senescence via p53/p21/p16 signaling Axis. J Proteome Res. 2018:17:1091-100

41. Beausejour CM, Krtolica A, Galimi F, Narita M, Lowe SW, Yaswen P, Campisi J. Reversal of human cellular senescence: roles of the p53 and p16 pathways. EMBO J. 2003;22:4212-22.

42. Dreesen O, Chojnowski A, Ong PF, Zhao TY, Common JE, Lunny D, Lane EB, Lee SJ, Vardy LA, Stewart CL, Colman A. Lamin B1 fluctuations have differential effects on cellular proliferation and senescence. J Cell Biol. 2013; 200:605-17.

43. Yin X, Zhang J, Li X, Liu D, Feng C, Liang R, Zhuang K, Cai C, Xue X, Jing F, et al. DADS suppresses human esophageal xenograft tumors through RAF/MEK/ERK and mitochondria-dependent pathways. Int J Mol Sci. 2014;15:12422-41.

44. Wang Z, Liu Y, Takahashi M, Van Hook K, Kampa-Schittenhelm KM, Sheppard BC, Sears RC, Stork PJ, Lopez CD. N terminus of ASPP2 binds to Ras and enhances Ras/Raf/MEK/ERK activation to promote oncogeneinduced senescence. Proc Natl Acad Sci U S A. 2013;110:312-7.

45. Chung E, Kondo M. Role of Ras/Raf/MEK/ERK signaling in physiological hematopoiesis and leukemia development. Immunol Res. 2011:49:248-68.

46. Davies MA, Samuels Y. Analysis of the genome to personalize therapy for melanoma. Oncogene. 2010;29:5545-55.

47. Prasetyanti PR, Medema JP. Intra-tumor heterogeneity from a cancer stem cell perspective. Mol Cancer. 2017;16:41.

48. Lee SW, Lee MH, Park JH, Kang SH, Yoo HM, Ka SH, Oh YM, Jeon YJ, Chung $\mathrm{CH}$. SUMOylation of hnRNP-K is required for p53-mediated cell-cycle arrest in response to DNA damage. EMBO J. 2012;31:4441-52.

49. Yoon MK, Mitrea DM, Ou L, Kriwacki RW. Cell cycle regulation by the intrinsically disordered proteins p21 and p27. Biochem Soc Trans. 2012; 40:981-8.
50. Fischer M, Quaas M, Steiner L, Engeland K. The p53-p21-DREAM-CDE/CHR pathway regulates G2/M cell cycle genes. Nucleic Acids Res. 2016:44:164-74.

51. Coates PJ, Hales SA, Hall PA. The association between cell proliferation and apoptosis: studies using the cell cycle-associated proteins Ki67 and DNA polymerase alpha. J Pathol. 1996;178:71-7.

52. Unek G, Ozmen A, Mendilcioglu I, Simsek M, Korgun ET. The expression of cell cycle related proteins PCNA, Ki67, p27 and p57 in normal and preeclamptic human placentas. Tissue Cell. 2014;46:198-205.

53. Li C, Wu X, Sun R, Zhao P, Liu F, Zhang C. Croton Tiglium extract induces apoptosis via Bax/BCl-2 pathways in human lung Cancer A549 cells. Asian Pac J Cancer Prev. 2016;17:4893-8.

54. Liu ZH, Wang MH, Ren HJ, Qu W, Sun LM, Zhang QF, Qiu XS, Wang EH. Interleukin 7 signaling prevents apoptosis by regulating bcl-2 and bax via the p53 pathway in human non-small cell lung cancer cells. Int J Clin Exp Pathol. 2014;7:870-81.

\section{Publisher's Note}

Springer Nature remains neutral with regard to jurisdictional claims in published maps and institutional affiliations.

Ready to submit your research? Choose BMC and benefit from:

- fast, convenient online submission

- thorough peer review by experienced researchers in your field

- rapid publication on acceptance

- support for research data, including large and complex data types

- gold Open Access which fosters wider collaboration and increased citations

- maximum visibility for your research: over $100 \mathrm{M}$ website views per year

At $\mathrm{BMC}$, research is always in progress.

Learn more biomedcentral.com/submissions 